\title{
A Educação Patrimonial no Turismo Sertanejo de Base Comunitária
}

\author{
The Heritage Education in Sertanejo Tourism of Local Base
}

\author{
Luana Maria Cavalcanti Bispo (BISPO, L. M. C.) ${ }^{*}$
}

\begin{abstract}
RESUMO - Este artigo visa estabelecer uma reflexão teórica sobre o Turismo Sertanejo de Base Comunitária em diálogo com a Educação Patrimonial enquanto metodologia de apropriação no processo de conscientização, sensibilização dos moradores na estruturação da atividade turística que possui um perfil sustentável de atuação. A partir de uma revisão bibliográfica mostra-se a pretensa contribuição da Educação Patrimonial para o Turismo Sertanejo de Base Comunitária enquanto ação transformadora, focada no desenvolvimento social e no resgate cultural. Destarte, pretende refletir sobre a contribuição da memória individual e coletiva, da identidade e da cidadania, enquanto elementos que propiciam uma construção mais equânime à atividade turística, no despertar do sentimento de pertencimento, focado no processo do reconhecimento dos moradores a partir da cultura, do Patrimônio Histórico Cultural inerente às comunidades. No decorrer do texto não serão apresentados resultados, tendo em vista que não se teve como objeto uma experiência concreta, mas se propõe uma linha de pensamento convergente que demonstre como o Turismo Sertanejo de Base Comunitária pode apropriar-se da Educação Patrimonial no desenvolvimento de suas atividades.
\end{abstract}

Palavras chave: Turismo; Sertão; Educação; Patrimônio.

ABSTRACT - This paper aims to establish a theoretical reflection on the local base Sertanejo (country person) tourism dialoguing with heritage education while methodology of appropriation in the rising awareness process of the residents for the local base tourism activity which has a sustainable profile of action. From a theoretical review it shows the possible contributions of heritage education for local base tourism as a transformative action, it focus on the social development and in the cultural rescue. Thus, it intend to reflect on the contribution of individual and collective memory, of citizenship and identity, as elements that provide a more equitable construction the touristic activity in the awakening of belonging feeling, focusing in the process of residents recognition from the culture, from the historical and cultural heritage of these communities. During the text will not be showed results, considering that it did not have as object a concrete experience, but propose a line of convergent thinking which demonstrate how the sertanejo tourism of local base can appropriate of the heritage education and its activities.

Key words: Tourism; Sertão; Education; Heritage.

\footnotetext{
* Formação: Graduação em História pela Universidade Federal da Paraíba (UFPB); Especialização em Turismo de Base Local (UFPB) e Mestranda do Programa de Pós-Graduação em História (PPGH/UFPB). Atividade profissional: Técnico-Administrativo (UFPB); Tutora EAD da Pós-Graduação em Educação em Direitos Humanos (UFPB). Endereço físico para correspondência: Universidade Federal da Paraíba, Campus I, Programa de Pós-Graduação em História PPGH, Cidade Universitária, CEP: 58051-900 - João Pessoa - Paraíba (Brasil). Telefone para contato: (083) 8898-5583. E-mail: luanamcf@ hotmail.com
} 


\section{INTRODUÇÃO}

A região geográfica determinada como Sertão, que compreende as terras continentais do nordeste brasileiro mais afastadas do litoral, com clima tropical semiárido e típica vegetação de xerófilas que se adapta às altas temperaturas da região, tem sido alvo de estudos, projetos científicos, sociais que proporcionam visibilidade a uma área esquecida e espetacularizada pela mídia a partir do quesito "seca". São projetos, estudos que surgem para apropriar, despertar, sensibilizar a potencialidade de uma região, de uma população muitas vezes esquecida pelo poder público e pela sociedade que criam símbolos estigmatizados na pobreza, na fome, na falta d'água e esquecem-se de visualizar suas riquezas naturais, culturais e econômicas.

Ao tratar do Sertão, o imaginário se vê guarnecido de várias representações que são criadas pelas fotografias do solo rachado, do gado morto, do rosto marcado que ilustram os livros de História e Geografia da vida escolar das pessoas, pelo conteúdo das chamadas indústrias da seca (1877-1879) “objeto" de manipulação de verbas em que os políticos tiraram proveito da situação para fazer os seus redutos de votos durante períodos severos de estiagem (DA SILVA, 2003).

Paralelo a isto, uma imaginação fortemente marcada pelas reportagens denunciativas e um tanto quanto apelativas que a mídia apresenta ao tratar sobre o Sertão Nordestino, sempre propenso a um cenário de sofrimento, "escravo" da seca e da pobreza.

Essas imagens são fruto de julgamentos superficiais sobre a realidade do semiárido e dos interesses políticos das elites locais que explicavam a miséria, a fome e o atraso como produtos de condições naturais adversas, do clima, da terra e da formação de sua gente (DA SILVA, 2003, p. 361).

Muito além destes símbolos carregados de preconceito, de uma visão negativa de quem, na sua maioria, não conhece a região e corrobora com um senso comum, o Sertão nordestino não gira em torno da seca, ele é composto de uma vegetação diversa, de uma paisagem exótica, de vestígios rupestres e de uma cultura rudimentar que fortalece a identidade sertaneja culturalmente. Vale salientar que:

[...] a seca não é um fenômeno constante na região, o Sertão brasileiro não é predominantemente árido, não atravessa eternamente essa condição climática 
desprovida de água, não é definitivamente desértico e a estiagem ocorrida nas terras da região Nordeste é periódica, embora frequente. Com a chegada da chuva, a região muda visualmente. As terras ficam aptas para a prática agrícola, banhadas pela água em abundância armazenada nos açudes e rios que servem às plantações e animais. A paisagem luminosa reflete o verde da vegetação que transforma o ambiente. $\mathrm{O}$ povo sertanejo cultiva seus roçados e alimenta suas criações com as condições disponibilizadas pela natureza do lugar (ANDRADE, 2008, p. 1).

A cumplicidade com as tradições, que segundo Adalberto Santos (2011) tem um pouco a ver com a continuidade de antigas formas, sofrendo apenas a influência de processos de reorganização, demonstra a forte identidade do povo sertanejo com os lugares por ele habitado através das técnicas de produção utilizadas, juntamente com as ações culturais apreendidas e repassadas de geração a geração, no modo de subsistência e no modelo de ocupação do espaço, no uso dos recursos naturais que definem esta relação.

Ao tratar do Turismo de Base Comunitária, tem-se como objeto de atuação a comunidade, que, segundo Maldonado (2009, p. 28):

\begin{abstract}
Estabelecer a natureza de "a comunidade" implica definir os princípios, valores, normas e instituições que regem a forma de organização e convivência de um determinado grupo humano, que, por sua vez, os diferencia de outros atores da sociedade. O seu objetivo final é assegurar o bem-estar comum e garantir a sobrevivência de seus membros, preservando sua própria identidade cultural. Na esfera institucional, a comunidade rege-se por normas sociais, econômicas e políticas que regulam os processos de tomada.
\end{abstract}

Os membros das comunidades sertanejas são detentores de um saber popular, incorporado às paisagens identificadas por seus fortes elementos naturais. De características rústicas, evidenciadas na geomorfologia e cobertura vegetal xerófila da paisagem, o Sertão nordestino ainda possui alguns lugares livres dos cenários plastificados $^{1}$ da vida urbana contemporânea, outros, como o município de Cabaceiras, localizado no interior da Paraíba já possuem cenários criados pelo homem para servir a chamada indústria criativa e, consequentemente turística, ao criar cenários em que a população não se identifica, pois foram realizadas "modificações na cidade para se adequar ao roteiro feito pela própria prefeitura” (ANDRADE, 2008, p. 3) tornando-se, inclusive, a "Roliúde Nordestina". Entretanto, "estas transformações" "não vêm

\footnotetext{
${ }^{1}$ São criados pelos homens, desfazendo suas características originais, ou seja, eles são criados para a prática do turismo, a exemplo dos Parques aquáticos, dos resorts etc.
} 
deixando na cidade algo de mais substancial, que possibilitasse aos moradores melhorias nas condições de vida, de educação, como o auxilio de projetos ou peças para compor o próprio acervo do Memorial Cinematográfico, por exemplo.” (ANDRADE, 2008, p. 3).

Isto demonstra a utilização inadequada da imagem das cidades como produto de consumo para atividades econômicas, a exemplo do que vem acontecendo também com o turismo de praia e sol nas áreas litorâneas, pois:

[...] o planejamento turístico no Brasil tem priorizado as regiões litorâneas em detrimento das áreas interioranas do País. As principais consequências da concentração de recursos e equipamentos no litoral traduzem-se na avassaladora especulação imobiliária com descaracterização dos padrões arquitetônicos locais, marginalização das comunidades tradicionais e aceleração do processo de aculturação dos grupos sociais comunitários (SEABRA, 2001, p. 114).

Todavia, o Sertão tem sido foco desde 1985 de projetos que visam o chamado Turismo Sertanejo que corresponde, segundo Seabra (2001, p. 113):

[...] a uma forma de lazer fundamentada na paisagem natural, no patrimônio cultural e no desenvolvimento social das regiões interioranas do Brasil. Tem como principal objetivo promover a compreensão integrada do meio ambiente em suas múltiplas e complexas relações, envolvendo os aspectos naturais, socioeconômicos, culturais e éticos. De maneira bastante sintética, pode-se dizer que o Turismo Sertanejo se insere na categoria de turismo exótico, um misto de agroecoturismo, com ênfase na valorização da identidade cultural regional e na melhoria das condições de vida da comunidade local.

Este tipo de turismo corrobora com a perspectiva do Turismo de Base Comunitária que tem como foco o desenvolvimento social e econômico de determinadas comunidades a partir de uma prática sustentável, que diz respeito a um turismo "economicamente viável, que não destrói os recursos dos quais o turismo no futuro dependerá, principalmente o meio ambiente físico e o tecido social" (SWARBROOKE, 2000, p. 19).

Este tipo de turismo faz com que os moradores, a sua população endógena, sejam os agentes de todo o processo de estruturação e efetivação da atividade, a partir de uma organização que centre seus atrativos na cultura local de maneira tangível ou intangível, a fim de não apenas dar retorno financeiro, mas fortalecer identidades e 
proporcionar espaço para que ocorra um intercâmbio cultural com o Sertão, excluso das rotas turísticas do nordeste. "O desenvolvimento do turismo é uma das formas para impulsionar as economias locais, a partir da possibilidade concreta do aumento dos níveis de geração de trabalho e renda e, consequentemente, a diminuição do nível de pobreza local” (RODRIGUES, 2007, p. 52). "A finalidade da empresa comunitária não é lucro nem a apropriação individual dos benefícios que são gerados, e sim a sua distribuição equitativa, através do investimento em projetos de caráter social ou de produção" (MALDONADO, 2009, p. 31).

A implantação da atividade turística deve ser feita a partir da articulação conjunta de órgãos federais, estaduais, prefeituras, universidades, empresários e a mídia, que segundo Seabra (2003) possibilitará a partir da troca de experiências uma ascensão social do incremento na produção econômica de um local. Vale salientar que estes não serão os manipuladores da atividade, cabendo-os colaborar na divulgação, na instrução e nos meios de apoio à atividade. A maior articulação deve partir dos moradores que são os agentes de todas as etapas, pois todos os recursos turísticos encontram-se no local onde residem.

\footnotetext{
Hoje, portanto, não cabe mais o desenvolvimento concebido de fora para dentro, onde o olhar externo não reflete as necessidades internas e desejos da comunidade. Nem devemos seguir o chamado "desenvolvimento clássico" onde "ser desenvolvido" é atingir certos parâmetros, certas possibilidades de consumo, metas do Ocidente. O mecanismo do desenvolvimento clássico prioriza os meios em detrimento das pessoas, representado pela busca de crescimento, do acúmulo de riquezas materiais e de uma civilização racional (RODRIGUES, 2007, p. 52).
}

Paralelo a esse caráter endógeno de forte ênfase para o desenvolvimento do Turismo de Base Comunitária, foca-se na contribuição da Educação Patrimonial a partir dos seus principais elementos orientadores - memória, identidade e cidadania - como metodologia de sensibilização para apropriação adequada da atividade Turística de Base Comunitária. Na Educação Patrimonial se trabalha com o despertar do sentimento de pertencimento nos indivíduos, que passam a se reconhecer na cultura tangível e intangível, no patrimônio local salvaguardado pela memória individual contribuinte da construção da memória coletiva através de processos de significação.

Visa-se refletir a partir dos elementos convergentes presentes no principio de sustentabilidade em que tais práticas comungam, como elas podem dialogar entre si 
visando um desenvolvimento social e econômico a partir de uma atividade consciente, em que as pessoas conheçam a História de suas comunidades e se reconheçam nelas como sujeitos históricos e como agentes indispensáveis na manutenção, preservação da cultura local, que é um dos atrativos principais o Turismo de Base Comunitária, em que o patrimônio deve ser visto de forma ampliada, incluindo-se o cotidiano, o corriqueiro, o simples.

Ligado ao Patrimônio Histórico Cultural nas suas diversas naturezas materiais (as construções, a arte rupestre, os utensílios, dentre outras) e os imateriais (o fazer, o saber (e assim por diante), deve existir uma ação que possa convergir para um diálogo entre o morador e o patrimônio, a fim de que eles se reconheçam, se identifiquem e se apropriem destes lugares como parte da sua história, de sua memória coletiva. Apropriada, a valorização virá sem que precise de ações impositivas, pois se o individuo consegue se enxergar na história, na cultura de sua comunidade, certamente, ao invés de destruir os bens culturais, ele vai preservar, afinal, supõe-se que é muito mais fácil cuidar do que a si próprio pertence. A partir de então, acredita-se que a atividade turística sertaneja será desenvolvida visando não apenas o lucro, mas a disseminação de uma cultura desconhecida, mas, supostamente imaginada por tantos.

\section{A EDUCAÇÃO PATRIMONIAL COMO INSTRUMENTO DE APROPRIAÇÃo PARA O TURISMO SERTANEJO DE BASE COMUNIÁRIA}

O Turismo Sertanejo tem sua atividade centrada na perspectiva de Base Comunitária, envolvendo a comunidade residente no desenvolvimento econômico e social de uma localidade. Compreende um trabalho voltado para as peculiaridades internas, em que seus elementos culturais, suas paisagens, o homem sertanejo são elementos de configuração da atividade.

A atividade turística no Sertão deve ser despertada a partir de um planejamento formulado pelos próprios moradores e não por consultores economicistas que vem de fora para dentro das comunidades com metodologias impositivas, afinal, "nesta proposta cabem menos os grandes empreendedores e mais os pequenos empresários, as associações comunitárias e a sociedade como um todo" (SEABRA, 2001, p. 115). 
O turismo comunitário questiona o mito do turismo como gerador de emprego e renda e denuncia as políticas centradas na atração de investimentos que não levam em consideração a participação e o desenvolvimento das comunidades locais (TURISOL, 2008, p. 3).

O Turismo de Base Comunitária tem um caráter social que potencializa o patrimônio natural, histórico, cultural e desperta valores muitas vezes esquecidos, além de contribuir com a preservação, torna-se uma alternativa econômica de complemento à renda familiar, ou seja:

[...] turismo praticado de uma forma que promova a qualidade de vida das populações residentes no local de destino; respeite a sociodiversidade da comunidade receptora, por meio da conservação da herança cultural das populações locais; e conserve os recursos naturais e paisagísticos desse local (OLIVEIRA, 2002, p. 8).

Mas, como colocar em prática esta atividade turística que se enxerga na relação entre indivíduo e o lugar sua força motriz, em que os moradores serão indispensáveis na construção dos roteiros, do mapeamento dos espaços enquanto atrativos turísticos, na estruturação das chamadas unidades hoteleiras familiares que são, na maioria das vezes, a casa do morador?

Conscientizá-lo quanto a isto não é um processo fácil, embora ele esteja ciente do retorno financeiro que a atividade possa proporcionar, é necessário despertá-lo de uma maneira que ele não vise apenas o lucro, mas a importância que a atividade pode estabelecer no reconhecimento da sua cultura, no fortalecimento de suas histórias e, consequentemente, da sua identidade.

Desta forma, a Educação enquanto prática transformadora, capaz de criar possibilidades para produção ou construção do conhecimento é partícipe na construção das ações do Turismo de Base Comunitária de maneira formal, atuando desde a formação escolar, e não formal, a partir de oficinas, cursos, treinamentos oferecidos à comunidade, pois é a partir destas ações que os moradores serão ouvidos.

Através dos seus relatos de memória são levados a compreender, que a partir dessa síntese de experiências - a qual Tedesco (2004) chama de memória - eles reflitam sobre a importância do lugar em que residem, do modo de vida que levam, da relação estabelecida com a natureza, que são parte da cultura que lhes são inerentes. De acordo 
com Ricardo Oriá (2013) em seu artigo "Educação Patrimonial: conhecer para preservar":

[...] a Educação Patrimonial compreende desde a inclusão, nos currículos escolares de todos os níveis de ensino, de temáticas ou de conteúdos programáticos que versem sobre o conhecimento e a conservação do patrimônio histórico, até a realização de cursos de aperfeiçoamento e extensão para os educadores e a comunidade em geral, a fim de lhes propiciar informações acerca do acervo cultural, de forma a habilitá-los a despertar, nos educandos e na sociedade, o senso de preservação da memória histórica e o consequente interesse pelo tema. ${ }^{2}$

Este é um processo de sensibilização em que os testemunhos, os relatos de memória dos indivíduos proporcionam contato com a materialidade ou imaterialidade do conjunto de elementos ritualísticos, de costumes, de modos de vida, de construções, da natureza, chamados de Patrimônio Histórico Artístico Cultural. Estes fazem parte da História da comunidade, seus moradores até sabem que existem, mas desconhecem a sua relevância. Quando estes elementos culturais são reconhecidos, apropriados, a partir da educação do olhar para a cultura, o individuo começa a ter uma consciência histórica que alimenta o sentimento de pertencimento e, por conseguinte, fortalece a sua identidade e o exercício da cidadania através do diálogo com os patrimônios comunitários.

O patrimônio comunitário é formado por um conjunto de valores e crenças, conhecimentos e práticas, técnicas e habilidades, instrumentos e artefatos, lugares e representações, terras e territórios, assim como todos os tipos de manifestações tangíveis e intangíveis existentes em um povo. Através disso, se expressam seu modo de vida e organização social, sua identidade cultural e suas relações com a natureza (MALDONADO, 2009, p. 29).

Então, pode-se afirmar que no Turismo de Base Comunitária a partir de seu caráter sustentável se busca exercer uma atividade de relevância social em que seus principais objetos de estruturação são o homem e o meio em que ele vive, é necessário que ocorra entre eles, ou seja, entre o homem e o meio uma relação afetiva, consciente, em que se busque preservar o patrimônio comunitário do lugar em que ele vive por ser parte da sua herança histórica.

2 Disponível em: <http://www.aprendebrasil.com.br/articulistas/articulista0003.asp>. Acesso em: 20/06/2013. 
Esse processo de conscientização e reconhecimento do individuo como sujeito histórico indispensável à manutenção da cultura do lugar é importante para que se barrem "intervenções externas que podem significar um aumento na sua dependência no mercado, um desmembramento de seus territórios, uma aceleração na perda de sua identidade cultural, um enfraquecimento de suas instituições e a coesão social que estas seguem" (MALDONADO, 2009, p. 28).

A fim de estabelecer uma reflexão em torno da relação entre o Turismo Sertanejo de Base Comunitária e a Educação Patrimonial, se discutirá sobre a tríade conceitual, memória, identidade e cidadania que embasa as ações da Educação Patrimonial, tendo em vista que, segundo Salvadori (2008, p. 26):

Toda e qualquer proposta de estudo da questão do Patrimônio Histórico Cultural que pretenda mais que o simples conhecimento dos bens oficialmente existentes, deve buscar estabelecer relações entre este e os conceitos de memória, identidade e cidadania, sem os quais se corre o risco de simplesmente reforçar determinadas lembranças que, consagradas pelo uso e pelo tempo, acabam sendo transformadas em sinônimo da verdade sobre o passado, construído de forma unilateral.

\section{MEMÓRIA, IDENTIDADE, CIDADANIA.}

Os três principais conceitos que dão embasamento à Educação Patrimonial, Memória, Identidade e Cidadania, são pilares na construção e efetivação do Turismo Sertanejo de Base Comunitária, tendo em vista o seu caráter social, que visa o exercício de uma atividade mais equânime, que valorize os bens patrimoniais comuns a todos da comunidade e proporcione um desenvolvimento humano e econômico distante de um perfil que tudo vende, propaga, mas que pouco conhece sobre a cultura do lugar, devido a mão de obra ser, em sua maioria, externa à população do meio.

Sendo assim, acredita-se que para discorrer sobre a metodologia da Educação Patrimonial como instrumento de apropriação do Turismo Sertanejo de Base Comunitária é necessário refletir sobre tais conceitos e como eles se ligam entre si.

Corrobora-se com a ideia apresentada por Tedesco (2004), que a memória é a síntese das experiências das pessoas, sua importância vem desde os tempos antigos, em que Heródoto, Tucídides utilizavam do testemunho ocular para narrar as Histórias que aconteciam em seu tempo. A memória era o substrato de toda experiência por eles 
presenciadas ou absorvidas, daí também advém as lapidadas retóricas, compostas por um conjunto de ideias bem decoradas e repassadas nos discursos políticos. Os relatos de memória, que são aqueles narrados pelas pessoas que vivenciam um acontecimento, um fato, era a principal matéria prima da História, hoje, a ciência histórica utiliza da memória de diversas maneiras, inclusive a partir da oralidade enquanto fonte ou metodologia da qual se chama de História Oral.

Quando os historiadores trabalham com a memória de um povo, de uma comunidade, a partir de indivíduos diversos, parte-se de uma memória individual para chegar a uma memória coletiva, comum a um determinado grupo (HALBWACHS, 2003). Com isto, busca-se aproximar da verdade o quanto possível a partir das possibilidades de interpretações que a problematização das fontes proporciona.

Seu atributo mais imediato é garantir a continuidade do tempo e permitir resistir à alteridade, ao 'tempo que muda', as rupturas que são o destino de toda vida humana; em suma, ela constitui um elemento essencial da identidade, da percepção de si e dos outros (ROUSSO, 1998, p. 94-95).

Os dados, as informações obtidas através dos diálogos proporcionados entre o patrimônio e o individuo, mediados pelo instrutor/professor/entrevistador, em meio a um processo de significação, com relação à importância de um passado presente seja nas lembranças, nas narrativas, nos vestígios apresentados e interpretados é que permitem aos sujeitos terem contato com essa memória que precisa, muitas vezes, ser insultada, despertada, questionada para ser reconhecida, para ser lembrada.

Quando as pessoas se colocam a disposição para lembrar, para relatar sobre um passado no hoje, ou seja, no presente, estão se permitindo não reviver o tempo, mas refazê-lo (BOSI, 1994), por isto, a partir deste refazer se (re) conhece de onde se vem, aonde se chega, quem são. Tem-se contato com continuidades e rupturas que dão formas a um "eu" a partir dos lugares, das pessoas e dos objetos no qual se relacionam, a partir de um "vivido experimentado como constituinte de a vida cotidiana, como constitutiva de um conjunto de valores implícitos e incorporados na cultura naquela que você experimenta ou faz parte" (TEDESCO, 2004, p. 105).

Estas impressões são marcas da vida, presentes na memória e que contribuem com a formação da identidade, com a resposta para quem são, afinal, "um homem sem passado, é um homem sem identidade" (CANDAU, 2012, p. 62), pois quando se olha 
para o passado e se enxerga neste ou naquele lugar, naquela prática, na experiência, no outro e se reconhece, enxerga-se os elementos constitutivos dos fatos, dos acontecimentos que são partes integrantes da História que se vive, da identidade que se constrói e que faz as pessoas serem iguais e diferentes ao mesmo tempo. Pois, a base da identidade comunitária também pode ser enraizada na consciência de pertencer a um determinado grupo étnico, seja este descendente ou não de povos que habitaram e possuíram vastos territórios do continente (MALDONADO, 2009, p. 28).

As identidades são construídas culturalmente, isto é, organizadas em torno de um conjunto específico de valores cujo significado e usos compartilhados são marcados por códigos específicos de autoidentificação: a comunidade de fiéis, os ícones do nacionalismo, a geografia do local (CASTELLS, 2003, p. 79).

De acordo com Salvadori (2008), a identidade quando analisada do ponto de vista histórico se presta a outras definições e sentidos, pressupondo o reconhecimento da mudança e da diferença, tanto em relação ao outro quanto em relação a si mesmo; é um processo mais que uma definição.

O patrimônio histórico-cultural, tomado como um dos suportes da memória coletiva, produz identidades sociais que são determinantes nos modos como os homens se apropriam da realidade que os cerca, apresentam e lutam por suas ideias, identificam-se com certas propostas, recusam outras (SALVADORI, 2008, p. 31).

Consequentemente, a partir do exercício de resgate da memória, que proporciona através do refletir, do lembrar o reconhecimento do individuo enquanto sujeito do lugar em que ele mora, que possui raízes, tradições, ocorre o contato com uma herança cultural que permanece no lugar a partir do seu cotidiano expresso nas manifestações do dia a dia, na forma de cozinhar, de plantar, de lhe dar com o tempo para a colheita, de organizar a sua casa, pois:

[...] a memória social ou coletiva, evidenciada a partir dos registros, vestígios e fragmentos, considerados conceitualmente como bens culturais de uma dada sociedade, constitui-se em referencial da identidade cultural e instrumento mediador entre sujeito histórico e a cidadania (TAMANINI, 1999, p. 340). 
Este reconhecer, este se enxergar é que permite um exercício mais equânime da cidadania, pois se há uma consciência de quem se é e da representação que o lugar estabelece a si mesmo, no outro, na comunidade em que se faz parte, os deveres e os direitos passam a estar muito além de um registro de nascimento ou de um título de eleitor, mas a partir de uma afetividade, pelo sentimento estabelecido com o lugar em que se habita, afinal, "à nossa sensibilidade pode nos propiciar melhores condições para sentir, interpretar e compreender este mundo" (DUARTE, 2001, p. 83) e, principalmente, aquele aonde se vive.

Agregados, estes conceitos se desenvolvem em ações significativas, de forte representação para a valorização da cultura histórica de um determinado lugar. Desta relação é que vem nascendo estudos e propostas no campo da Educação Patrimonial com relação a sua atuação enquanto metodologia de apropriação para atividades como as do Turismo Sertanejo de Base Comunitária e outras tantas no Ensino Formal, como os projetos desenvolvidos pelo Governo Federal do Brasil como o "Mais Educação 3" e em outras instâncias, a exemplo do projeto de Educação Patrimonial desenvolvido pela prefeitura municipal de João Pessoa de nome "O Futuro visita o passado" " entre os anos de 2009 a 2012.

A partir do momento em que se propicia o contato direto seja da criança, do adolescente ou da comunidade com a História e as manifestações da cultura do lugar em que ela reside, dentro de seus diversos elementos e significados, ocorre uma premissa para que os mesmos se identifiquem e se apropriem de sua chamada herança cultural. Isto pode ocorrer não apenas no Sertão, mas em qualquer comunidade em que a Educação Patrimonial seja colocada em prática.

Segundo Seabra (2003), o Turismo Sertanejo de Base Comunitária propicia um resgate, um incentivo a identidade cultural de um local, proporcionado com o fortalecimento das memórias e das histórias da população, que são reconhecidas nas suas manifestações artísticas, como na dança, no teatro, no artesanato e em outras

\footnotetext{
${ }^{3}$ Ação educativa do Governo Federal a partir de abordagens diversas que incluem reflexões culturais, artísticas, ambientais nas Escolas. Para mais informações, acessar: <http://portal.mec.gov.br/index. php?option=com_content\&view $=$ article \&id=16689\&Itemid=1113>.

${ }^{4}$ Projeto coordenado pela Secretaria de Educação e Cultura do município durante os anos de 2009 e 2010 realizado através das aulas de campo com alunos do Ensino Fundamental do município de João Pessoa pelas ruas do Centro Histórico que perpassa bairros como o do Varadouro, Centro, Tambiá e Roger. As visitas eram mediadas por estagiários dos cursos de História, Turismo, Arquitetura e Geografia, no qual a autora deste artigo atual enquanto estagiária no ano de 2010 e coordenadora no ano de 2011.
} 
religiosas, como as missas, as procissões, na fé inabalável que resguarda os dias na espera da chuva, da mudança, do novo sol.

Fomentar o turismo a partir do entendimento das memórias e histórias de um povo é considerar que aquilo que a comunidade entende como fundamental e representativo da simbologia local, precisa ser mantido como valorização das características da própria comunidade (CARNEIRO; MIDLEJ, 2011, p. 83).

O que acontece é que muitas vezes essas tradições são esquecidas, não há incentivo ou qualquer estímulo que demonstre o valor de suas representações culturais. Elas existem, estão ali, mas são vistas por um olhar que quando não trabalhado, sensibilizado, passa despercebido de importância e de utilidade.

Pode-se afirmar que a Educação Patrimonial ajuda a promover essa consciência, ela trabalha significando os elementos, apropriando olhares que são despertados a partir do cotidiano, dos objetos, das práticas e das manifestações corriqueiras, mas identitárias, memoráveis. Auxilia na inclusão mais adequada de uma comunidade na atividade turística, distanciando-a de um modelo técnico e essencialmente economicista, entretanto, mais afetivo e sustentável.

Todavia, as ações de Educação Patrimonial tornam-se válidas quando se enxerga a relação que existe entre o individuo e o lugar que ele habita, neste caso, o homem sertanejo que é sujeito da ação do Turismo Sertanejo de Base Comunitária. Este elo proporciona uma afetividade denominada de topofilia, ou seja:

[...] a topofilia é o nome do sentimento que desperta nas pessoas a vontade de preservar aquilo que lhe remete memórias afetivas, independente do impedimento legal de sua destruição, preservando não só a memória coletiva e sim todos os recursos já investidos para sua construção na época. Porém sua preservação só torna-se perceptível devido ao bom estado de conservação (DA SILVA; ANDRADE; PRIORI, 2009, p. 33).

Entretanto, o que se entende por "lugar", este meio que relaciona e desenvolve pontes com o individuo, criando elos afetivos e representações no qual a memória se alimenta?

[...] o lugar corresponde ao quadro de uma referência pragmática ao mundo, do qual lhe vêm solicitações e ordens precisas de ações condicionadas, mas é também o teatro insubstituível das paixões humanas, responsáveis, através da ação comunicativa, pelas mais diversas manifestações da espontaneidade e da criatividade (SANTOS, 1997, p. 15). 
Um determinado bairro, uma comunidade, uma cidade, são conglomerados urbanos ou rurais carregados de lembranças que dão sentido ao lugar que eles fazem parte, em que eles residem ou residiram, o espaço por si só não basta, por isto, é composto de um conjunto de elementos que lhes dão vida e lhe configuram muito além de uma delimitação geográfica espacial com recortes métricos.

Nas últimas décadas, tem-se ampliado o foco de pesquisas com a cultura no campo da sustentabilidade social. Por meio de programas de turismo têm se evidenciado processos que visam o desenvolvimento local (PEIXER; TAMANINI, 2007). O que possibilita compreender de forma integrada o ambiente e suas diversas e complexas relações, sobretudo ao que corresponde a cultura do homem sertanejo e ao setor produtivo a ele agregado (SEABRA, 2001).

Ao se atentar para a memória de um povo, foca-se numa sensibilização que levará a preservação dos bens culturais pertencentes à comunidade que está sendo sensibilizada. Esta preservação é fruto de um processo consciente, ou seja, as ações não são impostas, mas são dialogadas através de uma linguagem que possa levar o morador de um local a entender a importância do patrimônio material e imaterial tanto para sua história individual, como para sua coletividade.

As ações inerentes à Educação Patrimonial atuam como mediadoras entre a comunidade e o patrimônio, com a finalidade de sensibilização para que as pessoas possam entender a importância da cultura de um local, das heranças culturais que são deixadas em forma de registros tangíveis, como as construções, e as intangíveis que são as representações mais espirituais, subjetivas, que estabelecem identidade e fazem com que um indivíduo se reconheça e valorize o que lhe é de direito.

A educação patrimonial aparece como proposta inovadora e necessária. Não se trata, é claro, da criação de mais uma disciplina a ser incluída na grade curricular. Trata-se, isto sim, de um processo constante de resgate do passado social, da releitura daquilo que permaneceu e de compreensão dos processos que levam a esta seleção (SALVADORI, 2008, p. 36).

\section{OBSERVAÇÃO, REGISTRO, EXPLORAÇÃO E APROPRIAÇÃO}

Entretanto, como colocar as ações da Educação Patrimonial à comunidade? Afinal, a teoria não se move sem a prática, por isto, é necessário pensar na atuação da 
Educação Patrimonial na comunidade a partir de três etapas que compõem o processo de conscientização, sendo estas a observação, o registro e a exploração.

\begin{abstract}
A partir dessas etapas é possível promover propostas de aprendizagem, que agreguem tanto adultos quanto crianças. Assim, cria-se uma relação de afeto entre a comunidade e seus patrimônios, de modo que preservá-los passa a ser algo importante e prazeroso para todos os indivíduos da comunidade (OLIVEIRA; WESCESLAU, 2009, p. 9).
\end{abstract}

A etapa de observação atua com a percepção sensorial dentro dos sete sentidos das pessoas em que os moradores deverão ser estimulados por meio de perguntas, jogos, experimentos, relatos, ou seja, de dinâmicas que os envolvam e façam com que eles explorem ao máximo os bens patrimoniais de sua comunidade. Este é o primeiro momento, "a observação do objeto quando propõe que sejam feitos exercícios de Percepção sensorial do objeto onde se identifica sua função e/ou significado social" (PACHECO, 2010, p. 3 grifo nosso).

O registro é a maneira pelo qual o morador expressará o que pensa, o que visualiza através de um desenho, de uma fotografia, de uma música, de uma poesia, de um mapa o seu pensamento, seu conhecimento sobre os bens culturais da sua localidade, como ele se vê a partir deles. "Este segundo momento solicita a anotação das informações que o próprio objeto oferece. Isso pode ser realizado de diferentes formas e com diferentes níveis de complexidade, como o desenho, a descrição verbal ou escrita, a construção de maquetes etc." (PACHECO, 2009, p. 3).

A terceira etapa consiste na exploração, que é o momento de reflexão sobre o que há produzido sobre a comunidade em que eles residem, como ela é vista, que lugar ela ocupa na região em que se encontra. Esta fase ajuda a despertar o senso critico, interpretando os símbolos e seus significados. "O que se deseja é que o aluno pesquise em outras fontes para completar as informações sobre o objeto" (PACHECO, 2009, p. $3)$.

$\mathrm{Na}$ última etapa, a de apropriação, o morador vai por a sua criatividade em prática ao demonstrar o que foi apreendido durante as fases anteriores, estimulando-o externar o seu entendimento de preservação, valorização sobre os bens culturais que lhes fazem parte, por meio de uma expressão, de uma apresentação que cause reconhecimento, identidade e de um prévio planejamento elaborado pelos mesmos para atuação da atividade turística em sua localidade. "Essa tarefa demanda uma releitura do 
objeto em diferentes linguagens esperando-se que o público da ação de educação patrimonial faça uma recriação dos significados do objeto e se sinta afetivamente envolvido com ele" (PACHECO, 2009, p.3).

Este processo de sensibilização utilizado na Educação Patrimonial não se resume nestas quatro etapas, elas são parte de sustentação do processo, é o arcabouço principal das demais atividades que partem da herança cultural individual a fim de chegar à coletiva.

A partir dessas etapas é possível promover propostas de aprendizagem, que agreguem tanto adultos quanto crianças. Assim, cria-se uma relação de afeto entre a comunidade e seus patrimônios, de modo que preservá-los passa a ser algo importante e prazeroso para todos os indivíduos da comunidade (OLIVEIRA; WESCESLAU, 2010, p. 10).

Para Grumberg (2007), as atividades propostas através das dinâmicas estabelecidas com os moradores de uma comunidade que estão sendo sensibilizados, têm como um dos seus objetivos lembrar que tudo o que o homem produz é cultura e que ele é o principal agente no processo de preservação da memória de sua comunidade, polida por experiências como estas que reavivam a consciência coletiva.

Estruturalmente, a implantação do Turismo Sertanejo de Base Local precisa de algumas orientações, porque diferente do turismo de sol e mar que exige uma infraestrutura de acesso, hospedagem e outras regalias, a intenção associada ao turismo sertanejo é justamente trazer o turista para participar da vida no Sertão, viver uma experiência próxima dos modos e costumes cotidianos do morador.

\footnotetext{
A característica distinta do turismo comunitário é sua dimensão humana e cultural, vale dizer antropológica, com objetivo de incentivar o diálogo entre iguais e encontros interculturais de qualidade com nossos visitantes, na perspectiva de conhecer e aprender com seus respectivos modos de vida (MALDONADO, 2010, p. 29).
}

O desenrolar das atividades da Educação Patrimonial em que o sujeito é o morador e o objeto é a memória, permite que sejam identificados os chamados lugares de memória, expressão formulada pelo francês Pierre Nora (1993), e (re)pensada, (re)elaborada ao longo do tempo a partir de uma visão mais ampla de inserção, da sede que tem se aguçado em (re)memorar, pois se vive numa sociedade sem memória, em que "se habitássemos ainda nossa memória, não teríamos necessidade de lhe consagrar 
lugares. Não haveria lugares porque não haveria memória transportada pela história" (NORA, 1993, p. 8).

Estes lugares de memória são descobertos não apenas das construções de cunho oficial erguidas muitas vezes pelo poder público, mas pela memória da comunidade que os revelam a partir das marcas, das lembranças deixadas a partir das experiências num determinado lugar, pode ser desde a Igreja matriz da cidade, até uma simples esquina. "São verdadeiros patrimônios culturais, projetados simbolicamente e podem estar atrelados a um passado vivo que ainda marca presença e reforça os traços identitários do lugar" (ANDRADE, 2008, p. 2).

A representatividade dos "lugares de memória" converge com as palavras de Seabra (2001) que definem que são nestes lugares onde acontecem as manifestações culturais de raízes populares que se fazem mais espontâneas, transpirando inteligências imaginativas, construindo e dando vida à paisagem, enriquecendo-a de bens materiais e imateriais.

A contribuição destes lugares tão marcados de lembranças, de acontecimentos, de narrativas, de imaginação, além dos seus recursos naturais é que torna o Sertão um lugar de potencialidade para o desenvolvimento do Turismo de Base Comunitária. Tal atividade revigora identidades sucumbidas pelo mundo da globalização, onde o homem é iludido com a ideia de deslocamento a metrópole, distanciando-se de sua comunidade nativa e desconhecendo o aproveitamento e a oportunidade que lhe pode ser consentida com a apropriação de atividades em sua região.

\section{CONSIDERAÇÕES FINAIS}

O enfrentamento do Sertão Nordestino com base na sua "ferida mais viva" é sem dúvida a seca, não se nega que a mesma atrapalha em alguns momentos a vida dos sujeitos, moradores daquela região que sobrevivem com latas d'água na cabeça, alimentando-se do que ainda sobra, quando não, de farinha e doações, tornando-se muitas vezes o fator maior de imigração dos habitantes do Sertão para outras localidades, principalmente as metrópoles. 
Entretanto, a potencialidade natural do lugar é inegável para quem lá já esteve, a paisagem exótica é convidativa, sobre contrastes da vegetação, animais e solos que compõem um cenário com casas de taipa, de barro, fogão a lenha, gado no pasto e obras feita de pedras, verdadeiras esculturas da natureza. É um segredo vinculado a cada região, a cada sítio, a cada estrada de barro em que se acompanha o pôr do sol.

A atividade turística de base comunitária surge como proposta inovadora que visa o desenvolvimento econômico do Sertão, mas, principalmente seu desenvolvimento social, o resgate de uma autoestima perdida em sua maioria pelo sofrimento, pela longevidade de suas terras que se tornam foco do poder público apenas em época de eleição, quando não, são esquecidas.

Quando se pensa nesse Turismo de Base Comunitária para o Sertão que tem um perfil, como bem foi discutido, diferente daquele do Turismo de Massa, tendo em vista que visa um caráter sustentável no seu exercício, é normal que se ocorra um estranhamento, uma resistência por parte da população, tendo em vista que as boas intencionalidades quando chegam a lugares como estes, estão sempre sendo recebidas com desconfiança, devido aos interesses políticos que circundam o lugar e que tornam as pessoas descrentes. Por isto, acredita-se que para a atividade ser colocada em prática seja necessária uma aproximação com os moradores a fim de estabelecer confiança e conscientização, visando que eles se sintam seguros, valorizados e confiantes na sua realização.

Quando se visa trabalhar a Educação Patrimonial com o cotidiano de um lugar, resgatando autoestima a partir do olhar para suas práticas corriqueiras, para a memória dos indivíduos, que para eles parecem simples, mas que é matéria prima indispensável na construção da atividade, vai envolvendo o morador e despertando-o para suas potencialidades locais que podem se tornar atrativos para quem não conhece o lugar e que, somente ele, com o seu conhecimento vivenciado, experimentado, passado de geração a geração deverá ser o agente turístico adequado na disseminação da cultura do lugar, guiando os visitantes com a propriedade do que se diz.

Aos poucos, com um processo de fortalecimento da identidade a partir do trabalho com a memória, a apropriação vai tornando-se consistente através de um exercício de conscientização que visa o desenvolvimento da comunidade a partir de uma 
natureza organizativa interna, sentindo-se seguros e valorizados, os indivíduos se sentirão mais encorajados para a sua realização.

Estas propostas do Turismo de Base Comunitária no Sertão estão chegando até eles através de alunos e professores das Universidades Federais, a exemplo do trabalho do professor Giovanni Seabra do Departamento de Geografia da Universidade Federal com a ONG CAATINGA ${ }^{5}$ que está colocando em prática o turismo sertanejo na cidade de Oricuri em Pernambuco e em outros municípios da Paraíba, e do próprio Ministério do Turismo ${ }^{6}$ quando propõe programas de incentivo ao Turismo de Base Comunitária.

Entretanto, as propostas não surgem apenas destas formas, gestores de empresas privadas com interesses estritamente capitalistas, que observam as comunidades como potencialidades para o desenvolvimento da atividade turística a partir de suas riquezas naturais, visando o morador como mão de obra barata também estão atentos. Por isto, é necessário instruir tais moradores, despertá-los antes que intervenções com estes perfis venham a acontecer.

Destarte, a Educação Patrimonial não é a solução para tudo, não é isto que se está afirmando aqui, mas a sua natureza social, de valorização histórica busca sensibilizar o olhar do sujeito para a sua cultura, para o seu patrimônio, objetos de grande valor à História de uma comunidade.

Estes elementos de natureza cultural, histórica podem ser partícipes no despertar de uma atividade mais igualitária, com princípios de preservação e força de vontade proveniente do reconhecimento do individuo enquanto agente incansável na luta por valorização e disseminação da sua cultura.

Este exercício proveniente da Educação Patrimonial deve ser contínuo e permanecer em diálogo em uma comunidade em todas as gerações, para que o Turismo de Base Comunitária tenha sempre algo novo para apresentar, mesmo se baseando no antigo modo de viver. Sendo as duas práticas, a Educação Patrimonial e o Turismo de Base Local de caráter Sustentável, em que o capital social é foco de seus exercícios, complemento e não sobreposição de uma à outra.

\footnotetext{
${ }^{5}$ Mais informações em: <http://201.2.114.147/bds/bds. nsf/2D272AD6A4ACF26103256F97004A382C/\$File/NT000A3602.pdf>.

${ }^{6}$ Mais informações no site do Ministério do Turismo: Dsiponível em: <http://www.turismo.gov.br/turismo/programas_acoes/Estimular_desenvolvimento_sustentavel_da_ativid ade_turistica/estruturacao_turismo_areas_priorizadas.html>.
} 


\section{REFERÊNCIAS}

ANDRADE, C. Lugar de Memória... Memórias de um Lugar: patrimônio imaterial de Igatu, Andaraí, BA. Revista Passos, Islas Canárias, v. 6, n. 3, p. 569-590, 2008.

ANDRADE, V. G. "Roliúde Nordestina" - um cenário de formação dos sujeitos. Revista de História e Estudos Culturais, v. 5, n. 1, p. 1-15, 2008.

ANDRADE, M. Era uma vez dois sertões: A representação do Sertão nordestino nos filmes Vidas Secas, de Nelson Pereira dos Santos, e Baile Perfumado, de Paulo Caldas e Lírio Ferreira. Revista Temática, João Pessoa, v. 1, n. 4, 2008.

BOSI, E. Memória e sociedade - lembranças de velhos. 3. ed. São Paulo: Cia das Letras, 1994.

CANDAU, J. Memória e identidade. São Paulo: Contexto, 2012.

CARNEIRO, E. dos R.; MIDLEJ, M. M. B. Pensando o turismo sertanejo nos municípios de Cipó e Tucano (bahia) a partir dos conceitos de memória, história e identidade em seus Entrelaçamentos. In: Revista Cultur, v. 5, n. 2, Santa Cruz, 2011, p. 76-84.

CASTELLS, M. A era da informação: economia, sociedade e cultura - a sociedade em rede. 7. ed. São Paulo: Paz e Terra, 2003.

DA SILVA, R. M. A. ENTRE DOIS PARADIGMAS: combate à seca e convivência com o semiárido. Sociedade e Estado, Brasília, v. 18, n. 1/2, p. 339-360, jan./dez. 2003.

DA SILVA, M. P; DE ANDRADE, P. A. M; PRIORI, P. Topofilia e preservação territorial: identidade local e globalização. In. JORNADA DOS CURSOS DE HISTÓRIA, GEOGRAFIA E ARQUITETURA: ESPAÇO, HISTÓRIA E GLOBALIZAÇÃO, Bauru-SP, 2009, p. 28-34.

DUARTE, J. F. O Sentido dos Sentidos. Curitiba, Criar Edições, 2001.

GRUMBERG, E. Manual de atividades práticas de educação patrimonial. Brasília DF: IPHAN, 2007.

HALBWACHS, M. A Memória Coletiva. 2. ed. São Paulo: Centauros, 2003.

MALDONADO, C. O turismo rural comunitário na América Latina: gênesis, características e políticas. In: BARTHOLO, R.; BURSZTYN, I.; SANSOLO, D. (org.). Turismo de Base Comunitária: diversidade de olhares e experiências brasileiras. Rio de Janeiro: Letra e Imagem, 2009, p. 25-44. 
NORA, P. Entre memória e história: a problemática dos lugares. In: Projeto História. São Paulo: PUC, 1993, n. 10, p. 7-28.

OLIVEIRA, F. de; WENCESLAU, F. F. Educação Patrimonial e a Pesquisa Arqueológica do sítio "Casa de David Canabarro" em Santana do Livramento, RS. Disponível em: <http://jararaca.ufsm.br/websites/nep/download/TExtos/nep1.pdf>. Acesso em: 25/06/13.

OLIVEIRA, L. A. Mapeamento semântico do turismo sustentável: arquitetando um novo país. In: Prêmio SESC-SENAC de Turismo Sustentável, 2002, Rio de Janeiro.

ORIÁ, R. Educação patrimonial: conhecer para preservar. (s. d.). Disponível em: <http://www.aprendebrasil.com.br/articulistas/articulista0003.asp>. Acesso em: 20/06/13.

PACHECO, R. de A. Educação Patrimonial e Estudo do Meio: metodologias para o ensino de história na educação básica. In: ANPUH - SIMPÓSIO NACIONAL DE HISTÓRIA, 25, Fortaleza, 2009. Anais do XXV Simpósio Nacional de História, Ceará: Fortaleza, 2009, p. 1-6.

PEIXER, Z; TAMANINI, E. Turismo, cultura e identidade - a interface com os museus e a educação patrimonial. In: SEABRA, G. (Org.). Turismo de Base Local. João Pessoa: Editora Universitária/UFPB, 2007, p. 327-334.

RODRIGUES, L. Turismo de Base Comunitária: um caminho sustentável para poço redondo e Canindé do São Francisco no Semiárido Sergipano. 153 p. Dissertação (Mestrado em Desenvolvimento e Meio Ambiente) - Núcleo de Pós-graduação em Desenvolvimento e Meio Ambiente, Universidade Federal de Sergipe, Aracaju, 2007.

ROUSSO, H. “A memória não é mais o que era”. In: AMADO, J.; FERREIRA, M. (Coords.). Usos e abusos de história oral. Rio de Janeiro: FGV, 1998, p. 94-95.

SALVADORI, M. A. B. História, Ensino e Patrimônio. Araraquara, SP: Junqueira \& Marin, 2008.

SANTOS, A. Tradições Populares e Resistências Culturais: políticas públicas em perspectivas comparadas. Salvador: EDUFBA, 2011.

SANTOS, M. A Natureza do Espaço. Técnica e Tempo. Razão e Emoção. 2. ed. São Paulo: Hucitec, 1997.

SEABRA, G. Turismo Sertanejo - a cultura regional e o desenvolvimento local. . In: SEABRA, G. (Org.). Turismo de Base Local. João Pessoa: Editora Universitária/UFPB, 2001, p. 327-334.

O Turismo Sertanejo como alternativa econômica para o semiárido.

Revista Passos, Islas Canárias, v. 1, n. 2, 137-143, 2003. 
SILVA, R. ENTRE DOIS PARADIGMAS: combate à seca e convivência com o semiárido. Revista Sociedade e Estado, Brasília, v. 18, n.1/2, 361-385, 2003.

SWARBROOKE, J. Turismo Sustentável: conceitos e impacto ambiental. V. 1. São Paulo: Aleph, 2000.

TAMANINI, E. Museu Educação e Arqueologia: prospecções entre teoria e prática. São Paulo. Revista do Museu de Arqueologia e Etnologia. V. 3, p. 339-345, 1999.

TEDESCO, J. C. Nas cercanias da memória: temporalidade, experiência e narração. Caxias do Sul: EDUCS, 2004.

TURISOL. Rede brasileira de Turismo Solidário e Comunitário. Apresentação da rede, 2008. 30 p. Disponível em: <http://turisol.files.wordpress.com/2008/07/proposta.pdf〉. Acesso em: 04/06/2013.

Recebido em: 01-11-2013.

Aprovado em: 01-12-2013. 